Review Article

www.ijrap.net

\title{
DRUG STANDARDIZATION OF AYURVEDA, UNANI AND SIDDHA DRUGS
}

\author{
Rajeev Kurele*
}

Manager- QC, QA and F and D, Ayush DTL, Indian Medicines, Pharmaceutical Corporation Limited, Mohan, District Almora, Uttrakhand, India

Received on: 02/01/15 Revised on: 16/01/15 Accepted on: 06/02/15

\author{
*Corresponding author \\ Dr. Rajeev Kurele, MD (Ay.), Manager- QC, QA and F\&D, Person-In-charge, AYUSH DTL (Govt. approved Lab), Indian Medicines Pharmaceutical \\ Corporation Limited (A Govt. Of India Enterprise under ministry of AYUSH), Mohan (Via-Ramnagar), Dist.- Almora, Uttrakhand, India \\ E-mail: dr.rajeevimpcl@gmail.com
}

DOI: $10.7897 / 2277-4343.06239$

\begin{abstract}
India is a mother hub for development of Ayurveda, Unani, Siddha, Homoeopathy and other natural herbs based health science (AYUSH). Ayush Pharmaceutical industry is having great potential and opportunities for development in future. Standardization of drug means confirmation of its identity, quality and purity throughout all phases of its cycle i.e. shelf-life, storage, distribution and use by various parameters. Different techniques involved in standardization of crude/finished compound drugs so far, e.g. macroscopic methods, -microscopic methods, physical methods, chemical methods, biological methods. As we all know in our Ayurvedic system of medicines drug standardisation of Ayurvedic formulation is a big challenge. Clear cut guidelines have not been developed so far. Pharmacopeia testing protocol may be adopted for drug profiling. Drug standardization is required for the development of Indian system of Medicines (viz. Ayurveda) for identification of drug, purity of drug, safety of drug, strength of drug, efficacy of drug and to follow GMP and GLP standards as per various regulatory authorities. The national health authorities (national drug regulatory authorities, DCC) should ensure that all ASU pharmaceutical product subject to their control are in conformity with quality, safety, efficacy and that all premises and practices employed the manufacturing and distribution of these product comply with GMP standards, So as to ensure the continued conformity of the product with these requirements until such time as they are delivered to the end user.
\end{abstract}

Keywords: Drug, Standardization, Ayurveda, Unani, Pharmacopoeia, Testing.

\section{INTRODUCTION}

India is a mother hub for development of Ayurveda, Unani, Siddha; Homoeopathy and other natural herbs based health science (AYUSH). Ayush Pharmaceutical industry is having great potential and opportunities for development in future. Mainly in following herbal medicinal plants and their value added products well accepted in domestic and international market e.g. Ayurvedic medicines, Unani medicines, Siddha medicines, Homoeopathic medicines, herbal nutraceuticals, herbal cosmoceutical, herbal health drinks, dietary health supplements, medicinal plants / crude drugs, herbal extracts / concentrates, herbal veterinary medicines, health foods, AYUSH health care management, Ayurvedic panchakarma centre and health spa. Standardization of drug means confirmation of its identity, quality and purity throughout all phases of its cycle i.e. shelf-life, storage, distribution and use by various parameters. As we all know in our Ayurvedic system of medicines drug standardisation of Ayurvedic formulation is a big challenge. Clear cut guidelines have not been developed so far. So it is necessary to promote ISM manufacturing industry people for drug standardization work. Ministry of AYUSH, Govt. of India recently established Pharmacopoeial Commission of Indian medicines and Homoeopathy (PCIM and $\mathrm{H}$ ) for setting up drug standard of ASU and $\mathrm{H}$ Medicines ${ }^{1}$. To understand drug standardization following aspects need to be learnt and implement in our existing system.

\section{Method of Standardization}

There are different techniques involved in standardization of crude/finished compound drugs as;

1) Macroscopic methods,

2) Microscopic methods,

3) Physical methods,

4) Chemical Methods,

5) Biological methods

\section{Crude drugs Standardization}

Crude ASU drugs testing involve following testing protocol/steps ${ }^{2-15}$ for drug standardization;

1) Medico-botanical Survey/Identification, Habitat, Synonyms, Regional Names etc,

2) Collection and preservation of raw material,

3) Testing of drugs as per approved Pharmacopoeial testing protocol.

a) Identity by Pharmacognosy Profile, Chemical identification, TLC/ HPTLC finger print profile,

b) Purity by Physico-chemical profile,

c) Strength by active marker/assay estimation,

d) Safety by heavy metal profiling, Microbiological limit test analysis, Aflatoxins analysis and pesticide residue analysis,

e) Ayurvedic properties and action - rasa, guna, virya, vipaka, karma etc,

f) Important formulation,

g) Important therapeutic use,

h) Dose and Anupan (vehicle). 


\section{Pharmacognostic Drug Analysis}

Pharmacognostic tool ${ }^{16}$ apply for analysis of crude drug as;

a) Macroscopic examination,

b)Visual examination as size, colour, surface, characteristics, texture, other examination like odour, taste,

c) Macroscopic examination involve various steps as Preparation of sample, Inspection by microscopy, Inspection by colour filter of ground glass, Histochemical detection, Section study(T.S./L.S.)

d) $\mathrm{TLC}^{11} / \mathrm{HPTLC}$ finger printing,

e) Identification/marking for Phyto-chemicals.

\section{Compound drugs Standardization}

Compound ASU drugs testing involve following testing protocol $^{17-21}$ for drug standardization;

1) Literature survey/Drug reference,

2) Collection and preservation of raw material,

3) Testing of raw material by above testing protocol,

4) Definition,

5) Formulation composition,

6) Method of preparation (manufacturing SOP's),

7) Testing of compound formulation on under mentioned pharmacognostic and physicochemical testing protocol (Compound Drugs testing protocol) as;

a) Identity by description, microscopic profile if any, chemical identification if any, TLC ${ }^{11} /$ HPTLC finger printing profile,

b) Purity-Physico-Chemical profile,

c) Strength-active marker/Assay if any,

d) Safety by heavy metal profiling, microbiological limit test analysis, Aflatoxins analysis and pesticide residue analysis,

e) Storage

f) Therapeutic use

g) Dose and Anupan (vehicle)

h) Self life of drug by stability study.

There are various physicochemical testing employed for drug profiling which is depend on the specific characteristics of drug as per method given in Ayurvedic Pharmacopoeia of India (API) $)^{2-8,17-19}$, Unani Pharmacopoeia of India (UPI) ${ }^{9,20,21}$, Siddha Pharmacopoeia of India (SPI), USP (United state Pharmacopoeia), IP (Indian Pharmacopoeia) etc as

1) Determination of foreign matter,

2) Determination of ash value (at $500-800^{\circ} \mathrm{C}$ ),

3) Determination of extractable matter,

4) Determination of water and volatile matter,

5) Determination of moisture content (L.O.D. at $110^{\circ} \mathrm{C}$ )

6) Determination of bitterness value,

7) Determination of haemodynamic activity,

8) Determination of tannins,

9) Determination of swelling index,

10) Determination of foaming index,

11) Determination of pesticide residue,

12) Determination of Total chlorine and phosphorous, phosphates,

13) Determination of arsenic and heavy metal,
14) Determination of bulk density,

15) Determination of radio-active contamination,

16) Comparative TLC/HPLC/HPTLC/GC-MS,

17) Determination of in-organic content by ICP etc various test may be carried out for drug standardization.

In drug standardization chemist/Technical person must know state of art instrumentation technique, having knowledge of OQ (Operation Qualification), IQ (Installation Qualification), DQ (Design Qualification), PQ (Performance Qualification), Instrument manual and SOPs (standard operating Procedures) for Instrument Handling and maintenance, STP (Standard testing procedures) and WI (Work instruction for various common instrument used in the drug standardization or quality control process as $\mathrm{pH}$ meter, Single distillation unit, Double distillation unit, Soxhlet assembly, water bath, viscometer, tinto meter, bulk density apparatus, polari meter, referectometer, microscope, titration unit, hot air oven, magnetic stirrer, filtration unit, Infrared spectroscopy, moisture balance, Karl fischer tritrator, Muffle furnace, vacuum evaporator, dissolution apparatus, friability apparatus, hardness tester, top loading balance, autoclave, B.O.D., incubator, laminar flow, microbiological colony counter, antibiotic zone reader. In drug standardization work so many sophisticated instrument also used frequently as and when they are in need for application as paper chromatography setups, column chromatography apparatus, double beam spectrophotometer, HPTLC unit, HPLC unit, LCMS, G.C./M.S. unit, ICP unit. Microbiological testing ${ }^{17-19}$ also carried out for estmation of;

1) Total aerobic bacterial count,

2) Total yeast and mould count,

3) Presence of pathogens like Salmonella, P. aeruginosa, E. coli, S. aureus. Stability study ${ }^{19}$ also be carried out for drug standardization work for Real time stability studies (to see the changes in the quality standards at various intervals is found suitable for ascertaining the shelf life of the ASU medicines) in standard storage condition- Temp. $30^{0} \mathrm{C} \pm 2^{0} \mathrm{C}$, Relative humidity: $60 \% \pm 5 \%$ for \# $1 / 6 / 12 / 18 / 24 / 30 / 36$ months as per stability study testing protocol

\section{Drug standardization needs and challenges}

Drug standardization ${ }^{22}$ is required for the development of Indian system of Medicines (viz. Ayurveda) for following reason $^{23}$;

1) For Ayurvedic Physician, to cure disease, drug is only tool, medicine would be of good quality with highest efficacy and safety,

2) Identification of drug,

3) Purity of drug,

4) Safety of drug,

5) Strength of drug,

6) Efficacy of drug,

7) To follow GMP and GLP standards given by WHO.

Author review current reputed ISM drug manufacturing industry and author found following general difficulties and future challenges ${ }^{24}$ for ASU industry as; 
1) Lack of documented validation of products,

2) Lack of documented quality control procedures,

3) Lack of documented process validation,

4) Batch to batch variation in product,

5) Toxicity profile -not explained,

6) Efficacy -not scientifically proved and documented,

7) Quality assurance protocol -not properly designed,

8) Lack of world class treatment centers,

9) Lack of quality accreditation,

10) Lack of health Insurance approval,

11) Lack of well trained man power,

12) Lack of AYUSH technical personnel with scientific knowledge's,

13) Lack of consistency in quality in batch to batch production of products,

14) Product efficacy must be of well proven on latest scientific/regulatory requirement,

15) Product must be of highest safety and free from cross contamination,

16) Shortage of raw materials (GSP),

17) Adulteration in the raw materials and substitute issues,

18) Wild life originated product availability issues,

19) Escalation in raw materials price

20) Lack of written documentary evidence on clinical efficacy,

21) Lack of consistency in quality in batch to batch production of products,

22) Lack of a well defined and well orchestrated SOP,

23) Lack of scientific validation of the therapeutic claims,

24) Lack of scientific validation Safety claims

25)Customer satisfaction and confidence need assessment

26) To promote exports of Ayurvedic product globally

27)To upgrade Ayurvedic drugs and cosmetic manufacturers to compete in the international market on current scenario

\section{CONCLUSION}

Drug standardization and way forwards for ISM drug manufacturing industry or AYUSH, academia as the national health authorities (national drug regulatory authorities, DCC) should ensure that all ASU pharmaceutical product subject to their control are in conformity with quality, safety, efficacy and that all premises and practices employed the manufacturing and distribution of these product comply with GMP standards so as to ensure the continued conformity of the product with these requirements until such time as they are delivered to the end user. Government must be restructuring and strengthen the existing drug enforcement infrastructure

1) Development of common raw material sourcing centre (Herbal Mandi),

2) Development of Government medical store for ASU drugs,

3) Development of quality Research and development centre in the field of herbal medicine and other products,
4) Development of common facility centre for quality certification, bench marking and validation $\mathrm{F}$ and $\mathrm{D}$,

5) Development of International marketing support centers,

6) Development of data centre for Patent protection (IPR),

7) Development of GMP training and Technology transfer Centres,

8) Common facility centre for specialty production and packaging on contract manufacturing basis for development of entrepreneurship,

9) Soft skill development programme for hospital /Pharma Personnel,

10) Initiatives and incentive for quality accreditation.

\section{REFERENCES}

1. Information available on Web portal ministry of AYUSH, Govt. Of India, www.indianmedicnes.nic.in

2. The Ayurvedic Pharmacopoeia of India Part-I, Ministry of AYUSH, Govt of India

3. The Ayurvedic Pharmacopoeia of India Part-I,V-II (First Edition) V-I (First Edition), Ministry of AYUSH, Govt of India

4. The Ayurvedic Pharmacopoeia of India Part-II, V-III (First Edition), Ministry of AYUSH, Govt of India

5. The Ayurvedic Pharmacopoeia of India Part-I,V-IV (First Edition), Ministry of AYUSH, Govt of India

6. The Ayurvedic Pharmacopoeia of India Part-I,V-V (First Edition), Ministry of AYUSH, Govt of India

7. The Ayurvedic Pharmacopoeia of India Part-I,V-VI (First Edition), Ministry of AYUSH, Govt of India

8. The Ayurvedic Pharmacopoeia of India Part-I,V-VII (First Edition), Ministry of AYUSH, Govt of India

9. Unani Pharmacopoeia of India Part-I, V-I to V-VI, Ministry of AYUSH, Govt of India

10. Standardization of Botanical Volume-II, CCRAS, Ministry of AYUSH, Govt of India

11. TLC Atlas Part-I, V-I, Ministry of AYUSH, Govt of India

12. Standardization of Single Drugs of Unani Medicines Part-I to part V, CRUM, Ministry of AYUSH, Govt of India

13. Protocol For Testing of Ayurvedic Siddha and Unani Medicines Ministry of AYUSH, Govt of India

14. Laboratory Guide For The Analysis of Ayurveda and Siddha Formulation, CCRAS, Ministry of AYUSH, Govt of India

15. Safety/Toxicity Study Report of Some Ayurvedic Drugs, CCRAS, Ministry of AYUSH, Govt of India

16. Macroscopic and Microscopic Atlas of Pharmacopoeial Drugs PartI, V-V, Ministry of AYUSH, Govt of India

17. Ayurvedic Pharmacopoeia of India Part-II, V-I (First Edition) (Form), Ministry of AYUSH, Govt of India

18. Ayurvedic Pharmacopoeia of India Part-II, V-II (First Edition) (Form.), Ministry of AYUSH, Govt of India

19. Ayurvedic Pharmacopoeia of India Part-II, V-III (First Edition) (Form.), Ministry of AYUSH, Govt of India

20. Unani Pharmacopoeia of India Part-II, V-I Ministry of AYUSH, Govt of India

21. Unani Pharmacopoeia of India Part-II, V-II Ministry of AYUSH, Govt of India

22. Production of ISM Drugs With Current Good Manufacturing Practices, PLIM, Ministry of AYUSH, Govt of India

23. Kataria sahil et al, Standaridization of medicinal plant material, Int J. Res. Ayurveda Pharm 2011; 2(4): 1100-1109.

\section{Cite this article as:}

Rajeev Kurele. Drug standardization of Ayurveda, Unani and Siddha drugs. Int. J. Res. Ayurveda Pharm. 2015;6(2):192-194 http://dx. doi.org/10.7897/2277-4343.06239

Disclaimer

The views expressed by author in the article are his personal. Moksha Publishing House \& IJRAP does not have any relation to it. Moksha Publishing House does not hold any responsibility for the views expressed by the author. 